\title{
Portable Generator to Detect Cracks on Large Steel Structures: An Application of Inductive Thermography
}

\author{
Paul Dario Toasa Caiza ${ }^{1}$ (D) $\cdot$ Rüdiger Schwendemann ${ }^{2} \cdot$ Paola Calero $^{1} \cdot$ Thomas Ummenhofer $^{1}$
}

Received: 11 November 2020 / Accepted: 23 June 2021 / Published online: 7 July 2021

(c) The Author(s) 2021

\begin{abstract}
The demand of non-destructive methods to detect cracks caused by fatigue or brittle behavior in large steel structures has increased in the last years. Thermography based on electromagnetic induction is a promising method to detect cracks in weld seams and notches. This paper presents a portable experimental setup, which allows to perform in situ crack detection tests on large steel structures. The success of this configuration is based on the use of a highly efficient switched H-Bridge circuit, which can generate a square-wave output voltage with a fundamental frequency up to $100 \mathrm{kHz}$. Due to the low losses and the low necessary DC-link voltage, the circuit can be supplied by a lithium-ion battery, which allows a small and light setup. The generated square-wave output voltage supplies an air coil resulting in a high frequent triangle current. The induced electromagnetic field caused by the current signal generates eddy currents in the steel structure. Due to an increased current density of the eddy currents in the crack area, there is a measurable temperature increase near the crack. The resulting temperature field is visualized and recorded with an infrared (IR) camera, which shows in real time the occurrence of cracks.
\end{abstract}

Keywords Crack detection · Electromagnetic induction · Fatigue $\cdot$ Real time $\cdot$ Thermography $\cdot$ Portable

\section{Introduction to Pulse Thermography Based on Electromagnetic Induction}

The general principle of non-destructive testing (NDT) based on active thermography is defined as follows: activation of the specimen by thermal or mechanical means in order to obtain a significant variation of the temperature field which can reveal the presence of structural damages [1].

Particularly, the thermography based on electromagnetic induction performs the stimulation of a specimen through the generation of electromagnetic waves while an infrared (IR) camera records the variations of the surface temperature. From the recorded information it is possible to observe and analyze the magnitude and the phase images of the generated thermal fields. This procedure allows the detection of structural damages such as cracks or delaminations.

Paul Dario Toasa Caiza

paul.toasa@kit.edu

1 KIT Steel \& Lightweight Structures, Research Center for Steel, Timber \& Masonry, Karlsruhe Institute of Technology, Otto-Ammann-Platz 1, 76131 Karlsruhe, Germany

2 Institute of Electrical Engineering (ETI), Karlsruhe Institute of Technology, Engelbert-Arnold-Str. 5, 76131 Karlsruhe, Germany
According to the Faraday's law of induction, an induced voltage can be generated by the variation of an electric field within a coil [2]. The induced voltage opposes the creating flux by generating the eddy currents, which flow in electrically conductive materials and in conductors operating at high frequency, see [3,4]. On metallic specimens, the resulting eddy currents cause temperature variations in discontinuities or flaws on the surface located close to the coil.

A common experimental setup to apply this phenomenon is the lock-in thermography, which consists of a high frequency generator, a coil, an IR camera and a PC, although in some cases two generators and two coils have been used [5]. A high frequency sinusoidal voltage signal is generated and supplied to the coil, so that a high frequency current signal is generated. This current flowing through the coil generates a magnetic field around the coil, see Fig. 1.

When the coil is placed close to an electrically conductive material, eddy currents are induced in the material and flow through it. If the material contains a crack or discontinuity, the flow of the the eddy currents is disturbed so that they flow around the edges of the discontinuity and therefore their density increases in this region. Regions where eddy currents density has increased, experience a higher Joule 
Fig. 1 Principle of the eddy currents testing

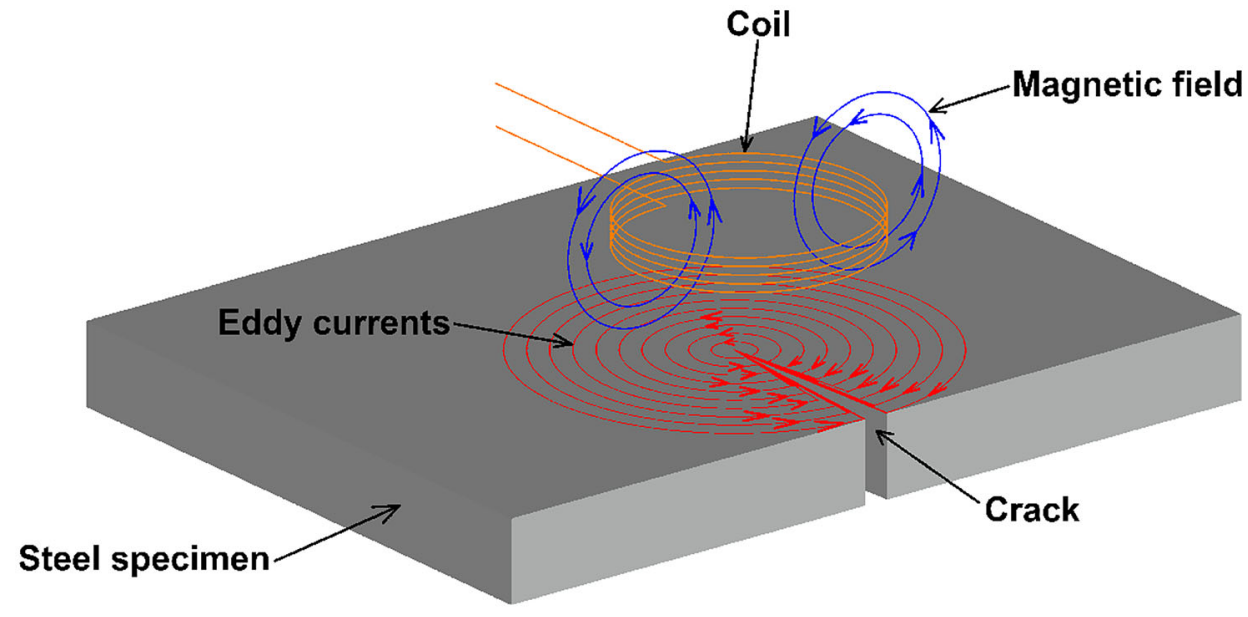

heating, which can be observed with an IR camera during the heating and the cooling down [6]. This heating is proportional to the square of eddy currents density and to the diffused heat $[3,7,8]$.

In other words, the eddy currents caused by this high frequency current signal leads to temperature variations at the surface of the specimen in the vicinity of the cracks.

The IR camera is synchronized with the generator and records the temperature variation during a period of few seconds. Afterwards, an image analysis of the amplitude images obtained with the IR camera is performed in order to acquire the phase images [5,9]. Based on the amplitude and phase images, structural damages can be observed.

This procedure has been applied in order to detect cracks only in metallic specimens such as steel billets [10], generator components [11], plumbing elbows [5], mechanical automotive components [12], steel gearwheels [9], turbine and compressor blades [4,13-16], specimens under thermal fatigue tests [17], thin aluminum plates [8], coated steel sheets [18] and tracks from railways, see [19,20].

In most of the cases, the coils surrounds the specimen and the variation of the electric field has been done by the generation of sine wave current signals from 100 to $550 \mathrm{kHz}$. With the exception of the method presented in [8], where the frequency of the signal was $50 \mathrm{kHz}$. Usually, for the generation of the corresponding current signal, an induction generator or a signal generator together with an analog amplifier are used. It is worth to mention, that these devices demand a high power supply and because of their weight they are not portable, see Table 1.

Due to the high power requirements of the equipment and the corresponding high weight and size, this kind of methodology cannot be applied to perform in situ a crack detection on large steel structures such as bridges, beams, wind towers, offshore structures, rail tracks or heavy duty cranes. These particular limitations demand the design and construction of a portable setup capable to perform a NDT in situ. The setup presented in this paper is based on a system which enables to sweep the signal frequency up to $100 \mathrm{kHz}$ and a RMS output current $I_{\text {out }}$ up to $20 \mathrm{~A}$ during the measurement [24]. Hence, it is possible to react according to the material behavior and thus the best pair of values from frequency and amplitude can be selected.

\section{Experimental Setup for Real Time Crack Detection on Large Steel Structures}

In order to overcome the limitations named in the previous section, a new hardware for the voltage supply of the air coil is necessary. As it was mentioned, NDT based on electromagnetic induction usually uses analog amplifiers or induction generators [15]. These converter topologies have the advantage that they can create an output voltage with a low Total Harmonic Distortion (THD). Thus, no additional filter is necessary to create a sinusoidal output voltage. In the present application, where an air coil is used to induce eddy currents in a steel structure, a low THD value does not result in any usable benefits.

Moreover, in order to build a portable system for NDT in real time a small and light system is desirable. Both converters, the analog amplifier and the induction generator, are very bulky and heavy. Hence, they are not suitable to build a portable test setup. Another important criterion for portable systems is the system efficiency because usually only a limited amount of energy is available in situ, such as bridges or off shore structures. Thus, a switched-mode converter topology, the H-Bridge converter, is developed for the given application.

\subsection{The H-Bridge Converter}

There are several requirements for the developed hardware. The initial goal is to achieve a high efficiency so that a 
Table 1 Necessary power for the electromagnetic induction setup

\begin{tabular}{ll}
\hline Power $(\mathrm{kW})$ & Specimens description \\
\hline 15 & Forged parts: spur gears and automotive components [12] \\
$10-15$ & Railway wheels and rails [19,20] \\
10 & Steel wires [21] \\
10 & Metal sheets from the auto body [22] \\
10 & Water pipes connections [5] \\
$5-10$ & Turbine blades [4,15,16] \\
5 & Hollow profiles with a circular cross-section made of IN718 [23] \\
2 & Aircraft compressor blades [14] \\
1,5 & Steel gears (d=125 mm) [9] \\
10 & Coated steel sheets [18] \\
\hline
\end{tabular}

battery-based system can be designed. Since a portable system is developed, the used voltage level should below 120 $\mathrm{V}$ so that the system is a protective low voltage system and thus no additional safety concepts are necessary. In previous tests with an $1200 \mathrm{~V}$ converter, it was shown that a voltage between 80 and $100 \mathrm{~V}$ is sufficient for an NDT based on electromagnetic induction [25]. Besides, the size and weight of the system are also important, because a handheld system should be designed which must be used in areas difficult to access. Furthermore, the coil structure and also the behavior of different materials are part of the investigation, so a variable system must be developed that is able to adjust the output current and frequency as well as the modes of operation. To satisfy all these requirements, an H-Bridge converter is developed according to the schematic shown in Fig. 2. The H-Bridge converter contains three parts: the Human Machine Interface (HMI), the signal processing part and the power electronics part. The power electronics part consists of the MOSFETs $T_{1}-T_{4}$, the gate-drivers, the heatsink and DClink capacitors. For the signal processing part a proprietary MAX10 board [26] is used.

On this board, the FPGA 10M08SAE144C8G from Intel is implemented. The FPGA has several tasks: It controls the operation mode of the MOSFET H-Bridge, it communicates via Fiber Optic Cables (FOC) with a central PC to facilitate automatic measurement routines controlled by the $\mathrm{PC}$, it controls the heatsink temperature of the MOSFET HBridge and finally it reacts on the commands of the user via the Human Machine Interface (HMI) of the converter. Thus, the H-Bridge converter can be controlled by the PC or manually over the HMI of the converter. By means of the HMI, the user can adjust the frequency of the output voltage, the voltage waveform and the operation mode. The developed prototype with the implemented HMI is shown in Fig. 3. The prototype has a length of $L=20 \mathrm{~cm}$, a width of $W=10 \mathrm{~cm}$ and a height of $H=7 \mathrm{~cm}$. The weight of the prototype is $850 \mathrm{~g}$ in combination with commercial available $120 \mathrm{~V}$ batteries with $360 \mathrm{Wh}$ and a weight of $1.9 \mathrm{~kg}$ the whole system has only a weight of $2.75 \mathrm{~kg}$.

As can be seen in Fig. 3, the power electronics part is enclosed by the housing of the prototype and only the HMI and the MAX10-board are freely available.

To reach a high system efficiency, the design of this power electronics part is crucial. Therefore, the different operation modes of the converter has to be considered. Hence, the different operation modes are first discussed in the following, before the design of the power electronics part is described.

\subsubsection{Operation Modes of the H-Bridge Converter}

The H-Bridge converter has two basic parameters: the switching frequency $f_{\mathrm{sw}}$ and the phase shift $\beta$. It operates with a switching frequency $f_{\mathrm{sw}}$ between 50 and $100 \mathrm{kHz}$ with fundamental frequency pulse. To adjust the amplitude of the output voltage $V_{\text {out }}$ and thus the output current $I_{\text {out }}$, a phase shift method with the phase shift $\beta$ is utilized. In Fig. 4 the output voltage $V_{\text {out }}$ and the output current $I_{\text {out }}$ for a phase shift $\beta=\pi / 2$ and $\beta=\pi$ is shown for an ideal air coil with $R_{\text {eq }}=0 \Omega$. The voltage $V_{\mathrm{a}}$ and $V_{\mathrm{b}}$ are the voltages of one phase leg, as can be seen in Fig. 2. The highest current occur for $\beta=\pi$.

Four different operating modes are superimposed on these two basic parameters: continuous mode, pulse mode, sweep mode and combination mode. In the continuous mode, the switching frequency and the phase shift are adjust and the output is activated.

In the pulse mode, the output switches between two different phase shifts $\beta_{1}$ and $\beta_{2}$. The switching frequency $f_{\mathrm{sw}}$ is constant. The time period within the inverter uses one phase shift is defined by the number of switching periods per phase shift. In Fig. 5 the measured output current $I_{\text {out }}$ for an exemplary operation in pulse mode is illustrated.

In sweep mode, a phase shift $\beta$, a start frequency $f_{\mathrm{sw}, 1}$ and a stop frequency $f_{\mathrm{sw}, 2}$ are defined. The switching frequency $f_{\text {sw }}$ is swept up and down between start and stop frequency 
Fig. 2 Schematic of the $\mathrm{H}$-Bridge converter

Fig. 3 Prototype of the H-Bridge converter

Fig. 4 Output voltage $V_{\text {out }}$ and output current for $\beta=\pi / 2$ (left) and $\beta=\pi$ (right)
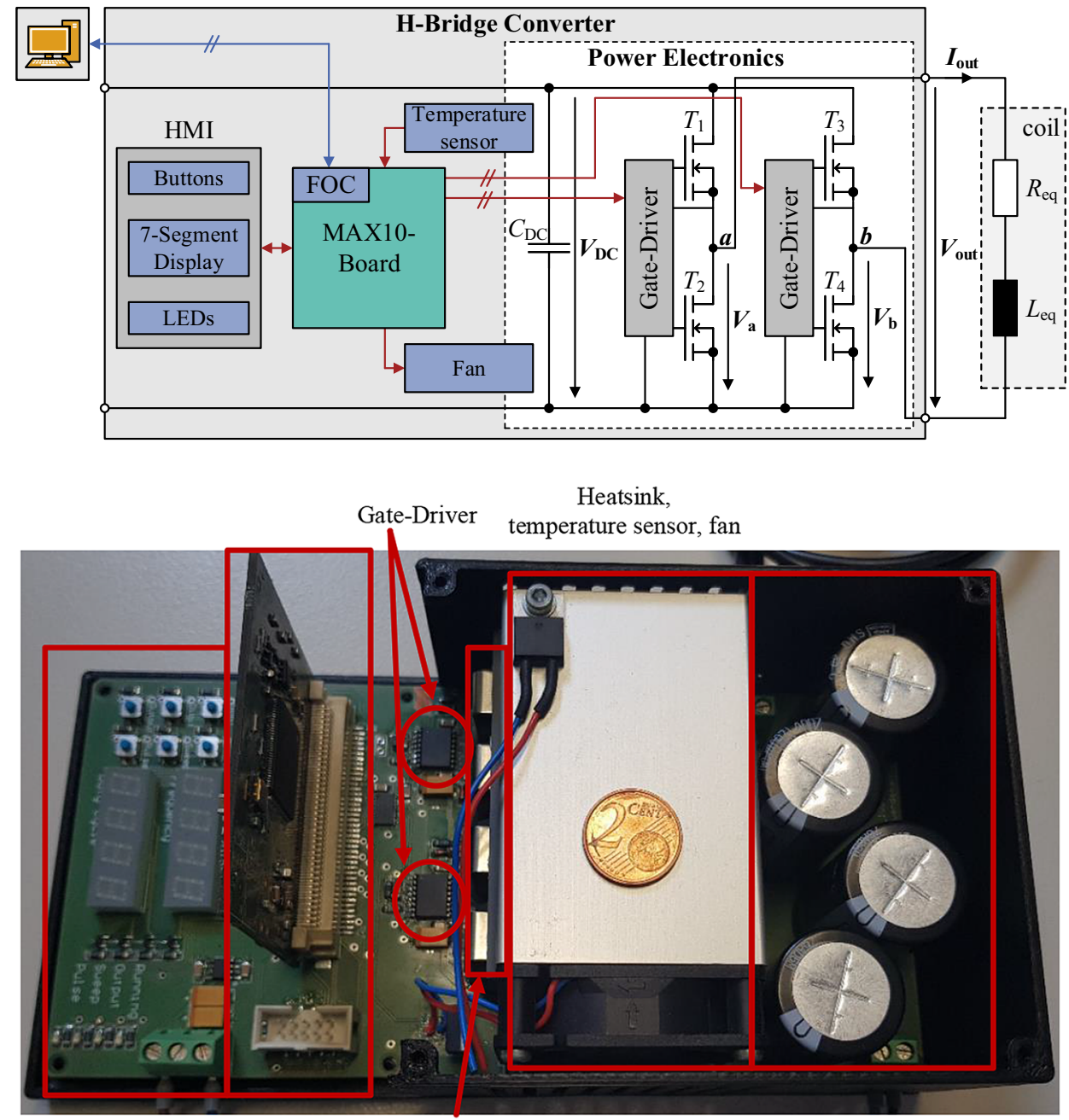

HMI MAX10-Board MOSFETs

DC-link capacitors

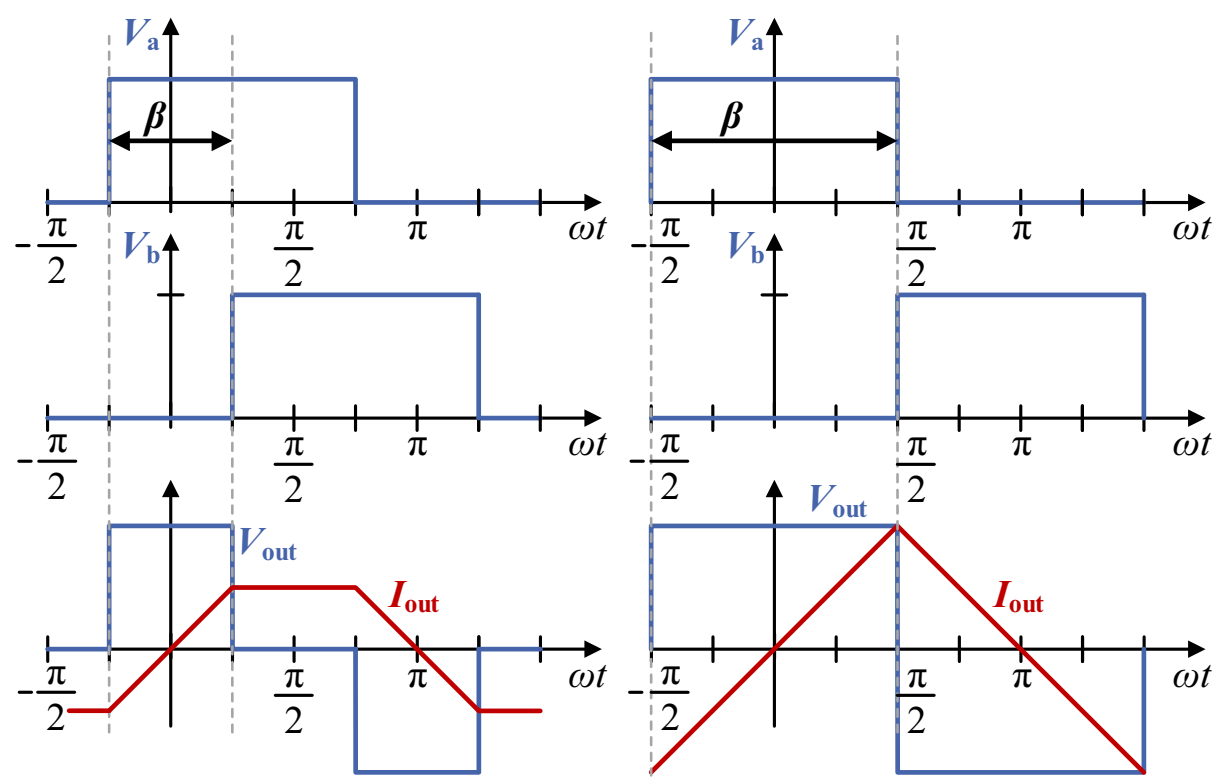


Fig. 5 Output current $I_{\text {out }}$ in pulse mode

Fig. 6 Configuration of the test scenario in Flux2D and the corresponding output currents $i_{\text {out }}$ of the converter

Fig. 7 Geometry of the specimen made from $\mathrm{S} 355 \mathrm{~J} 2+\mathrm{N}$ steel
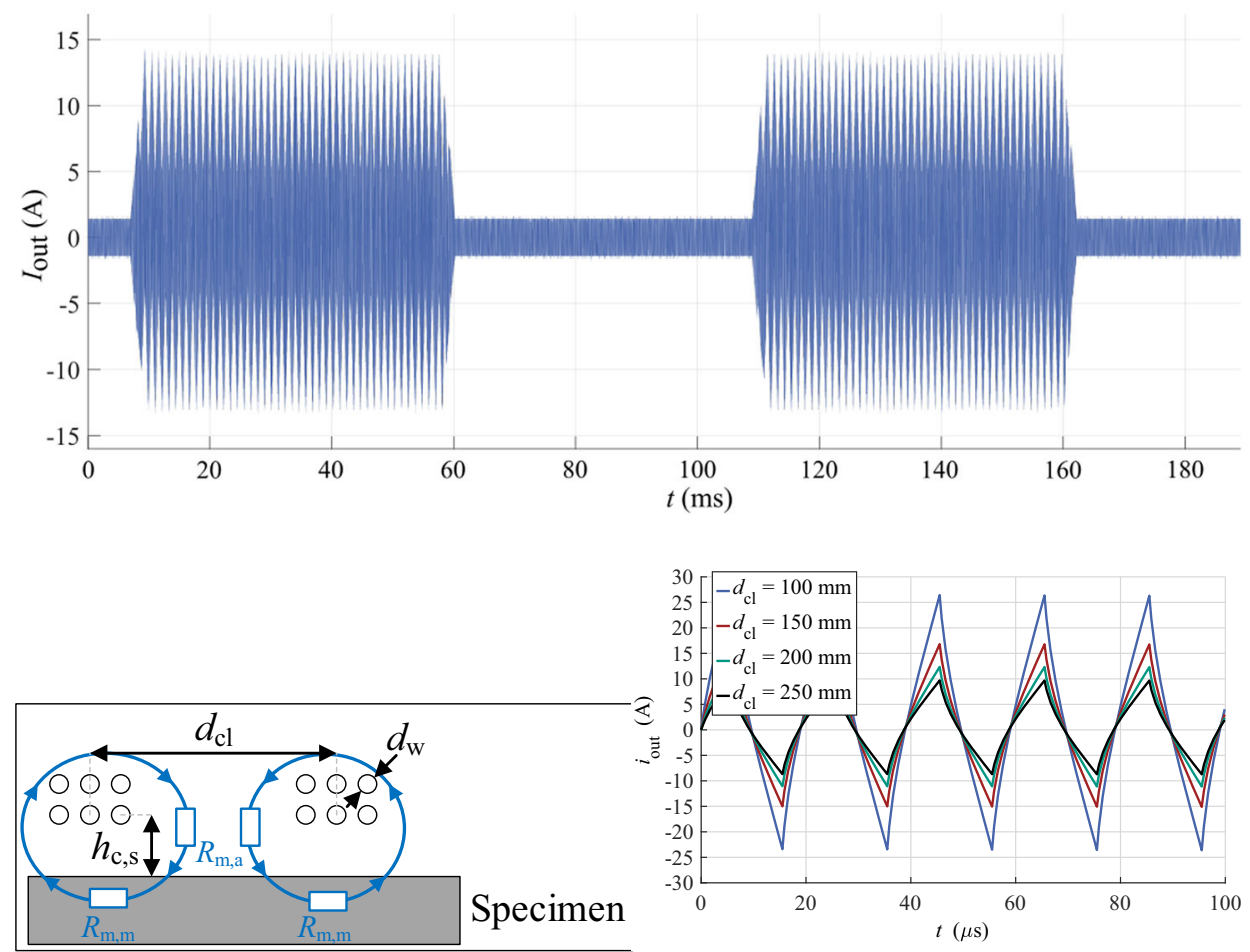

(a) Configuration of the test scenario in Flux2D

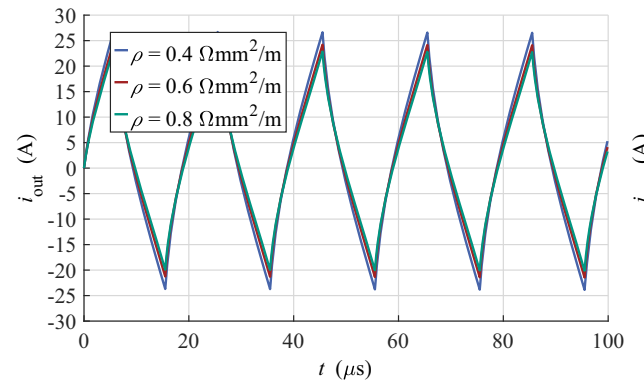

(c) Output current $i_{\text {out }}$ for different specific electrical resistance $\rho$ (b) Output current $i_{\text {out }}$ for different coil diameters $d_{\mathrm{cl}}$

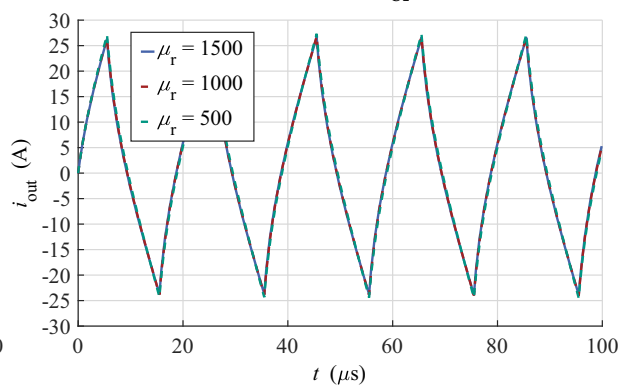

(d) Output current $i_{\text {out }}$ for different relative permeability $\mu_{\mathrm{r}}$

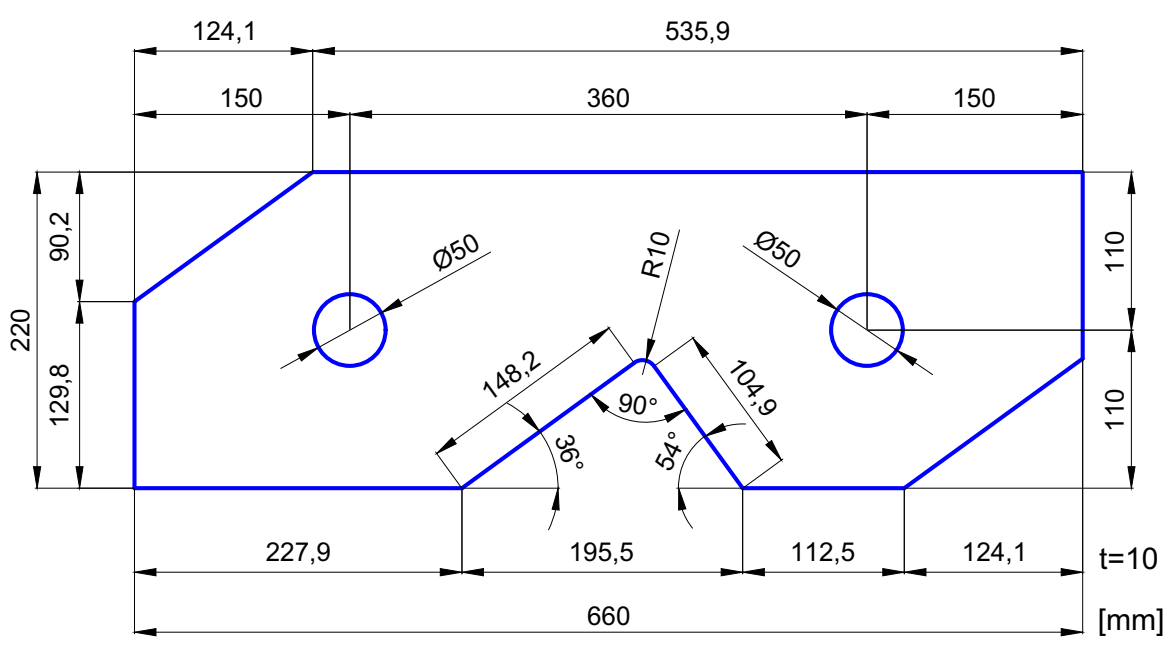




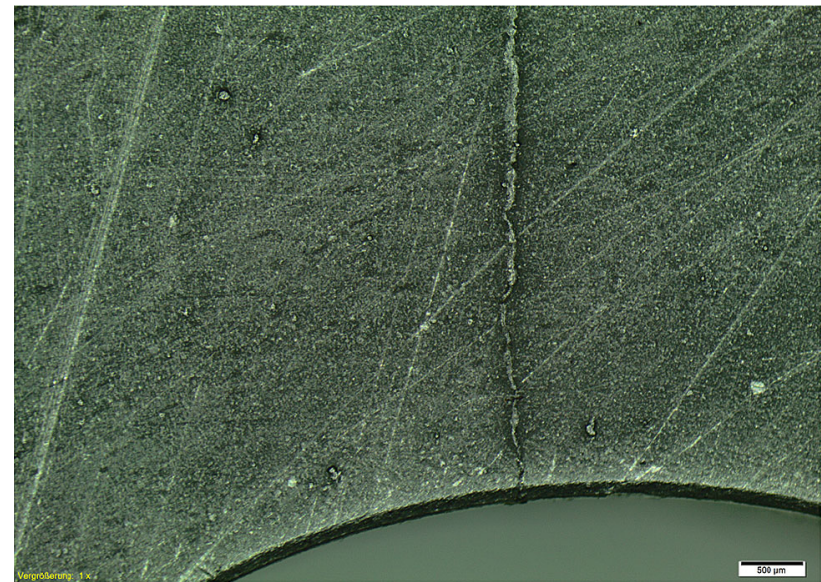

Fig. 8 Microscopic picture of the crack on the notch of the steel specimen. The length of the crack is $24 \mathrm{~mm}$ and its CMOD is around $25 \mu \mathrm{m}$

with a defined frequency step $\Delta f_{\text {sw }}$. For each frequency, a defined number of periods is used before the inverter makes a frequency step.

The last mode is the combination mode. In this mode a phase shift $\beta$ for one time interval is defined, in the second time interval $\beta=0$. Also, a start frequency $f_{\mathrm{sw}, 1}$ and a stop frequency $f_{\text {sw, } 2}$ are specified. For each pulse period a different switching frequency is used. As in sweep mode, the number of periods per frequency and the frequency step $\Delta f_{\mathrm{sw}}$ are specified. This mode is used to find the optimal switching frequency for the given steel specimen and coil configuration.

\subsubsection{Design of the Power Electronics Part}

For the design of the power electronics, the working point with the highest current must considered. As mentioned above, the highest current occur for a phase shift of $\beta=\pi$. In addition to the phase shift, the switching frequency $f_{\mathrm{sw}}$, the distance between air coil and the steel specimen $h_{\mathrm{c}, \mathrm{s}}$, the material of the specimen and the coil configuration must also be taken into account. The coil configuration itself has the following parameter: coil diameter $d_{\mathrm{cl}}$, the number of windings $w_{\mathrm{cl}}$ and wire diameter $d_{\mathrm{w}}$. To identify the worst case operation point, a magnetic analysis of the test scenario is performed with Flux2D, varying the distance between specimen and coil $h_{\mathrm{c}, \mathrm{s}}$, the coil diameter $d_{\mathrm{cl}}$ and the specimen material, i.e. the specific electrical resistance $\rho$ and the relative permeability $\mu_{\mathrm{r}}$. The number of windings $w_{\mathrm{cl}}$ is defined to the minimum of ten. The distance $h_{\mathrm{c}, \mathrm{s}}$ is varying between 4 and $40 \mathrm{~mm}$, the coil diameter $d_{\mathrm{cl}}$ between 100 and $250 \mathrm{~mm}$, the specific electrical resistance between 0.4 and $0.8 \Omega \mathrm{mm}^{2} / \mathrm{m}$ and the relative permeability between 500 and 1500 which are typical values for used steel types. The modification of the distance $h_{\mathrm{c}, \mathrm{s}}$ has no crucial impact on the maximum current value since the inductive behavior is dominant. The variation of the coil diameter $d_{\mathrm{cl}}$ strongly influences the maximum current, with the smallest diameter causing the highest current, as be shown in Fig. 6b. Thus, the material modification is analyzed with the smallest distance $h_{\mathrm{c}, \mathrm{s}}$ and smallest coil diameter $d_{\mathrm{cl}}$. In Fig. $6 \mathrm{a}$ the analyzed test scenario in Flux2D, in Fig. $6 \mathrm{c}$ the resulting current for different specific electrical resistance $\rho$ and in Fig. $6 \mathrm{~d}$ for different relative permeability

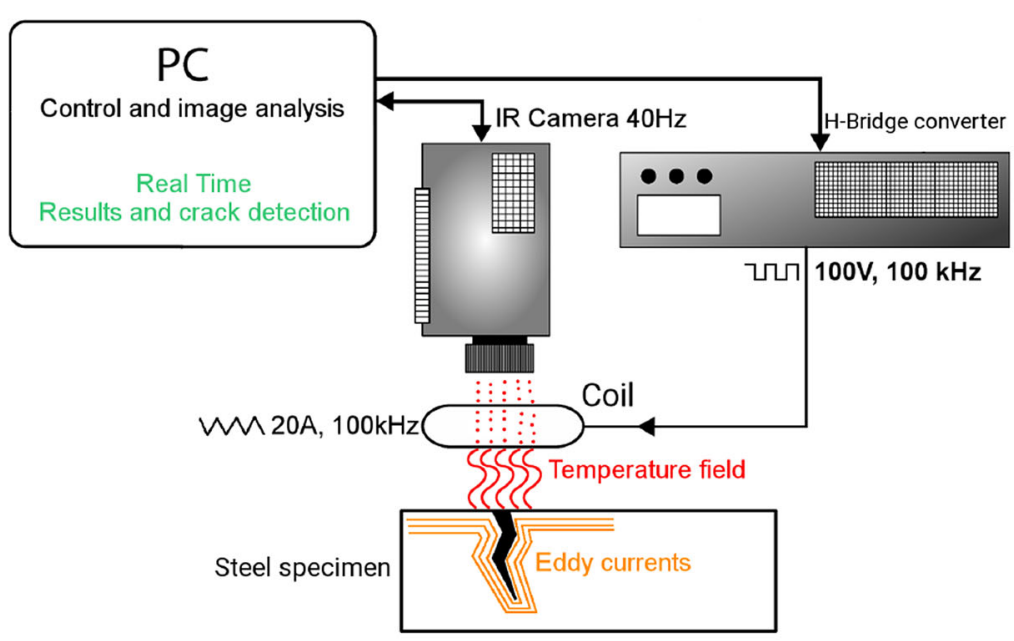

(a) Block diagram

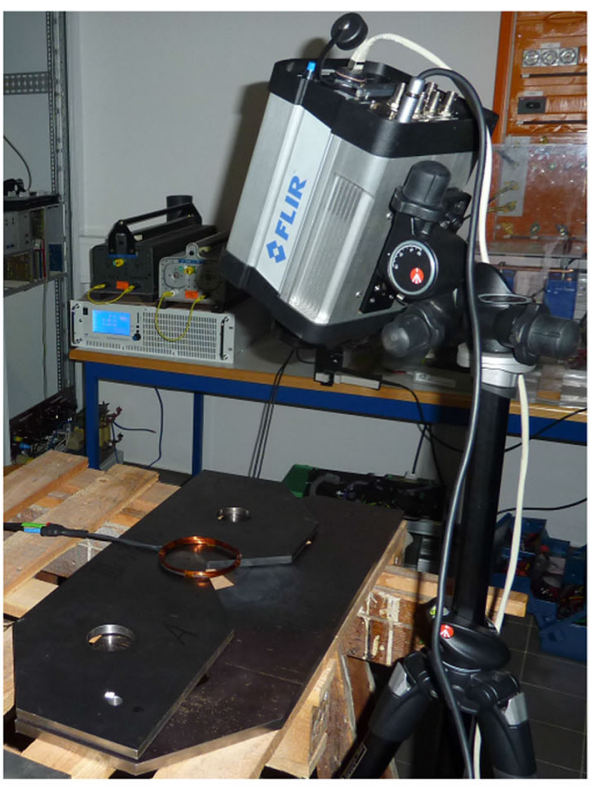

(b) Real assembly

Fig. 9 Experimental setup with a H-Bridge converter 
Fig. 10 Images of the crack visualization without moving the coil

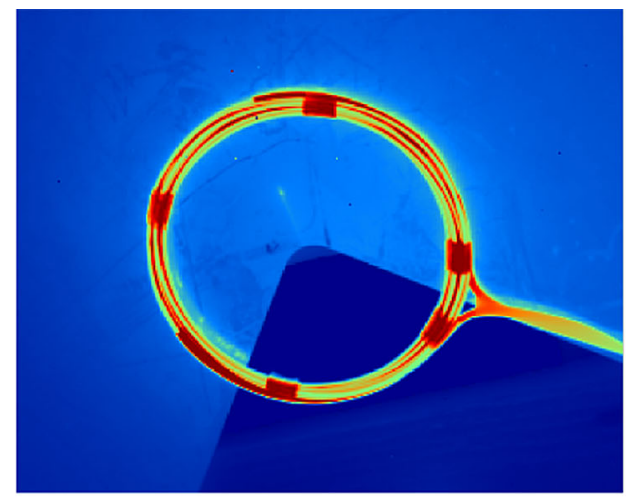

(a) $\mathrm{t}=3.6 \mathrm{~s}$

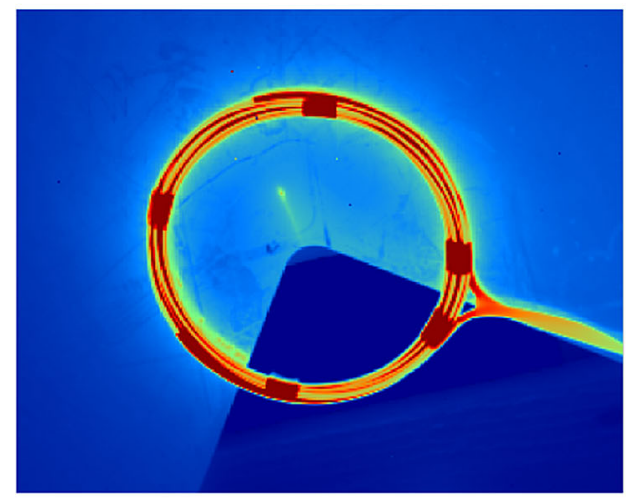

(c) $\mathrm{t}=8.2 \mathrm{~s}$

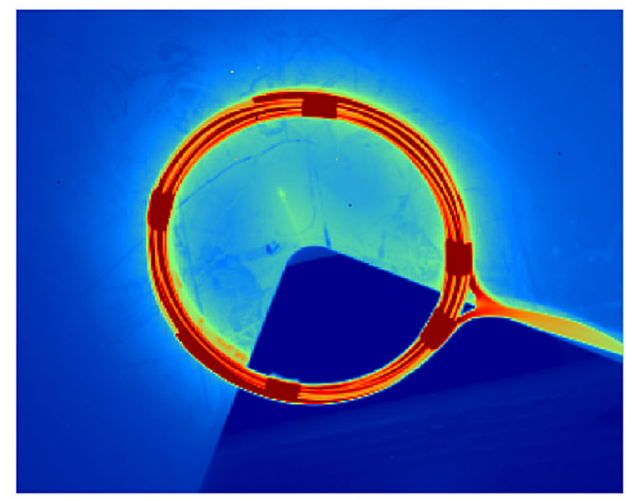

(e) $\mathrm{t}=13.3 \mathrm{~s}$

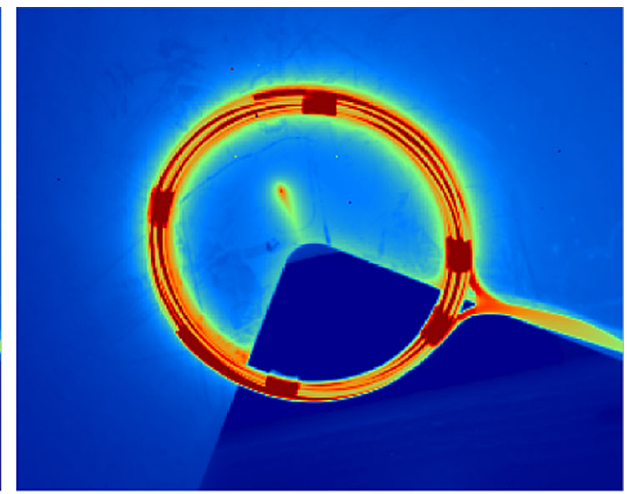

(b) $\mathrm{t}=5.0 \mathrm{~s}$

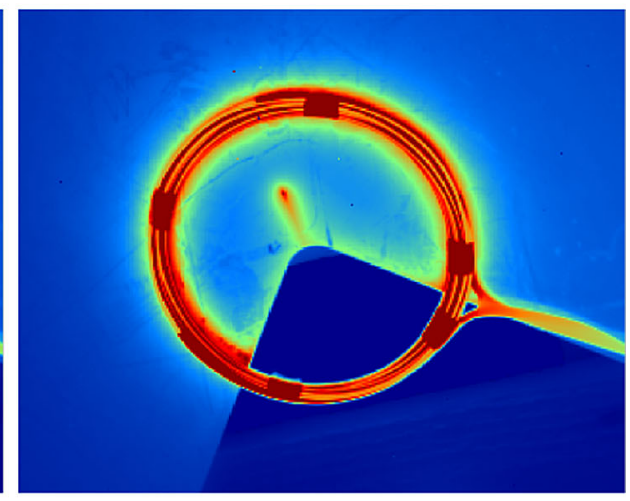

(d) $\mathrm{t}=9.75 \mathrm{~s}$

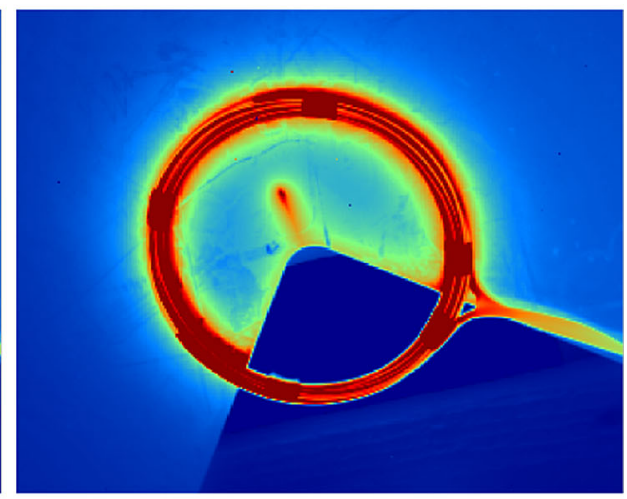

(f) $\mathrm{t}=14.9 \mathrm{~s}$ $\mu_{\mathrm{r}}$ are illustrated. As can be seen, the current is nearly triangular and the maximum amplitude of the output current $\hat{I}_{\text {out }}$ is $26 \mathrm{~A}$ for an specific electrical resistance $\rho$ of $0.4 \Omega \mathrm{mm}^{2} / \mathrm{m}$ and a relative permeability $\mu_{\mathrm{r}}$ of 1500 .

According to Fig. 6c, d, the change in electrical resistance $\rho$ and relative permeability $\mu_{\mathrm{r}}$ has almost no effect on the current. This can be explained by the fact that the path of the magnetic field is mainly in the air and thus the magnetic resistance of the air $R_{m, a}$ is dominant. Hence, a change of the material or rather the magnetic resistance of the material $R_{m, m}$ does not have a crucial impact on the resulting current.

With the knowledge of the output current, a loss analysis of the MOSFETs is possible. The losses are calculated according to [27]. The analysis is done with two SiMOSFETs and one SiC-MOSFETs. The $150 \mathrm{~V}$ Si-MOSFET "FDH055N15A" generates total power losses of $25 \mathrm{~W}$, the $200 \mathrm{~V}$ Si-MOSFET "IXTP150N15X4" $26 \mathrm{~W}$ and the $650 \mathrm{~V}$ SiC-MOSFET "C3M0015065D" $37 \mathrm{~W}$. Hence, the system is build with the 150 V Si-MOSFET "FDH055N15A". Besides 


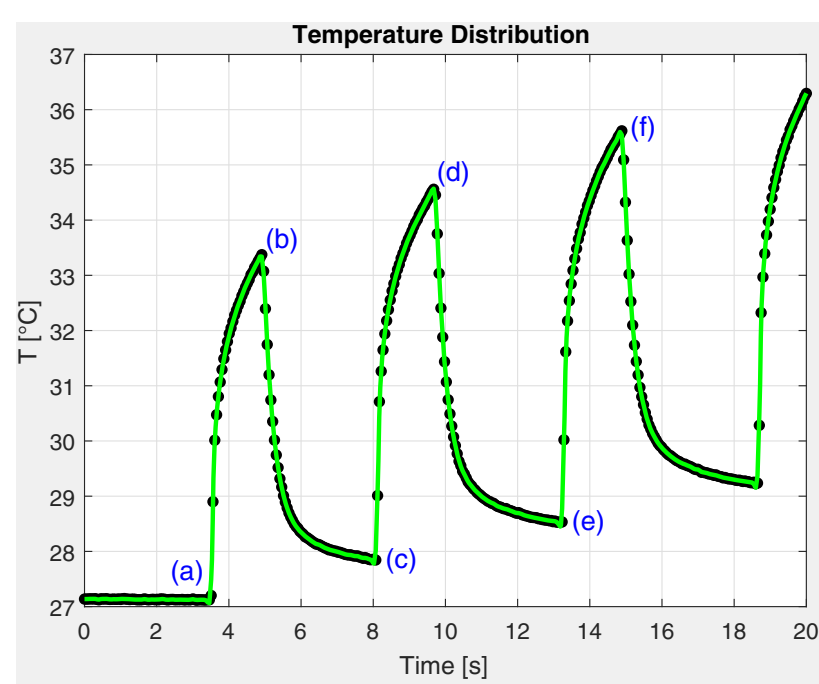

Fig. 11 Variation of the temperature in the crack tip. The points (a) to (f) correspond to the images shown in Fig.10

the MOSFETs, also the DC-link capacitor is crucial, because the main part of the output current $I_{\text {out }}$ is reactive current and oscillated between the DC-link capacitor and the air coil. The RMS-current of the DC-link capacitor is about $20 \mathrm{~A}$. Hence, four $200 \mathrm{~V}$ aluminum electrolytic capacitors with a maximum RMS current of $5.25 \mathrm{~A}$ are used.

By means of the developed H-Bridge converter in combination with the $360 \mathrm{Wh}$ battery and assuming that the average power consumption of the specimen is $200 \mathrm{~W}$, a portable system is available that can be used for about one hour on one charge.

\subsection{Steel Specimens}

In order to prevent structural damages and to reduce the cost of maintenance, it is very important to detect small cracks or defects in weld seams and geometrical notches of fatigue loaded steel structures.

During the experiments one specimen made of steel $\mathrm{S} 355 \mathrm{~J} 2+\mathrm{N}$ has been used, its geometry shown in Fig. 7 is the same as the specimen used in the research presented in [28].

The specimen is $10 \mathrm{~mm}$ thick and has a small fatigue crack at the notch. The crack was generated by a high cycle fatigue test, and it has a length of $24 \mathrm{~mm}$ and has a CMOD ${ }^{1}$ of around $25 \mu \mathrm{m}$, see Fig. 8 .

\footnotetext{
${ }^{1}$ Crack Mouth Opening Displacement.
}

\section{Experimental Results}

In order to compare the performance of the developed system based on the H-Bridge converter, the obtained results were compared with those obtained by applying a pulse thermography setup based on a linear system. This linear system includes a function generator HAMEG HM8131-2 and an audio amplifier ECLER DPA4000T [29]. The developed system includes the $\mathrm{H}$-Bridge converter and a laboratory power supply for the H-Bridge converter. Both systems use an air coil which was made of copper wire AWG 14 and has a number of winding $w_{\mathrm{cl}}$ of 10 and a coil diameter $d_{\mathrm{cl}}$ of $100 \mathrm{~mm}$. The measured inductance of the coil was $17 \mu \mathrm{H}$, and the corresponding magnetic field was $48 \mathrm{mT}$. Also, the IR camera FLIR SC4000 with a set recording frequency of $40 \mathrm{~Hz}$ and recording time of $10 \mathrm{~s}$ which lead to 400 thermographical images/frames was used. The block diagram of the test setup with the developed H-Bridge converter is shown in Fig. 9a and the real installation of the system in Fig. 9b. All of the tests were performed at room temperature and under natural light conditions in the laboratory as it is shown in Fig. 9b.

The use of the linear system caused several difficulties during the experiments. The high power dissipation of the linear system resulted in a high temperature rise of the air coil. Furthermore, due to the high power dissipation, continuous operation was not possible because of the over-temperature of the linear system itself. On the other hand the system based on the H-Bridge converter worked continuously and the temperature of the coil increased less than in the previous case.

Since the increase of the air coil temperature was low, performing the tests under natural light conditions did not cause problems regarding the reflection, this fact also represents an advantage of the setup proposed in this article. When a linear system was used, the high temperature reached on the coil caused reflection on the specimen, so that in order to avoid visualization problems the crack region was covered by applying Graphit 33 spray which is a conductive lacquer based on graphite.

Under these conditions, two kinds of experiments on the steel specimen described above were performed, see [30].

\subsection{Static Test}

The first kind of testing was performed keeping the coil over the area which contains the fatigue crack. The temperature variation in this area was recorded with the IR camera without moving the coil. The output of the voltage supply was switched on/off every second.

The visualization of the crack was possible every time when the voltage supply was switched on, see Fig. 10.

The variation of the temperature in the crack tip is shown in Fig. 11. The distribution of the temperature shows clearly 
Fig. 12 Images of the crack visualization while the coil is moving

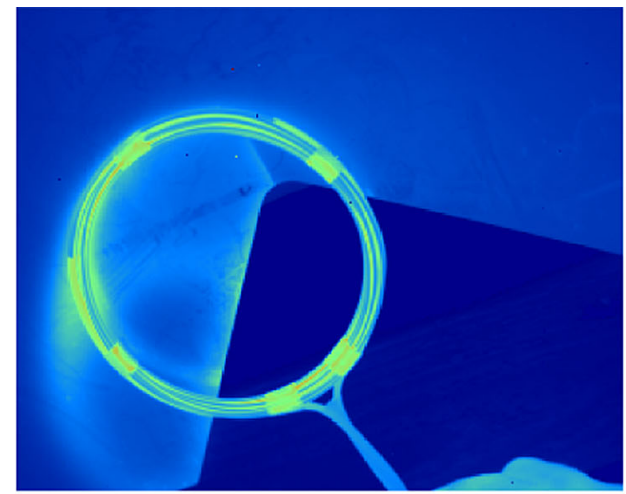

(a) $\mathrm{t}=5.0 \mathrm{~s}$

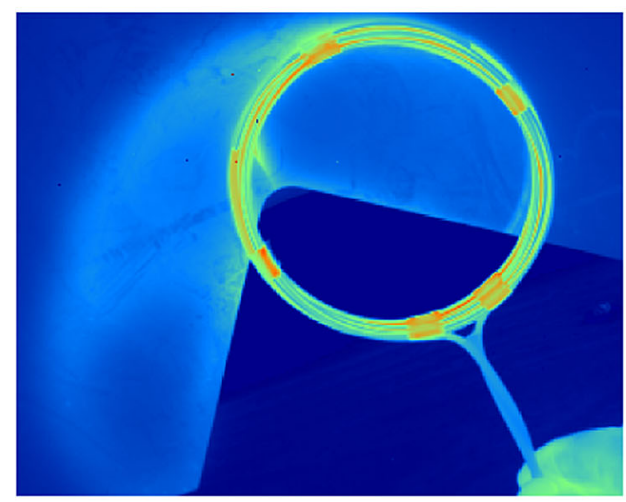

(c) $\mathrm{t}=7.7 \mathrm{~s}$

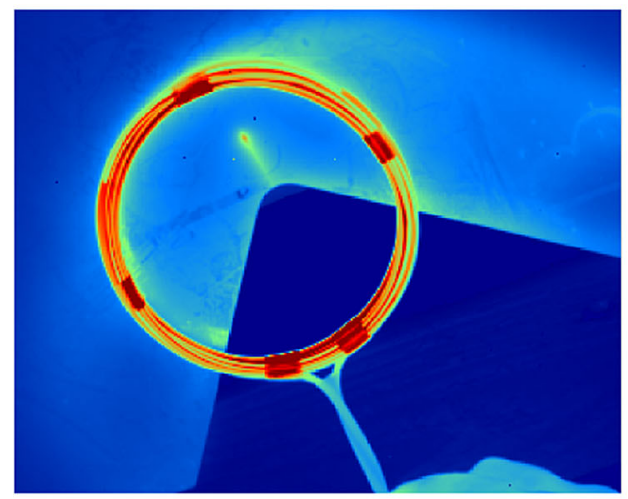

(e) $\mathrm{t}=14.8 \mathrm{~s}$

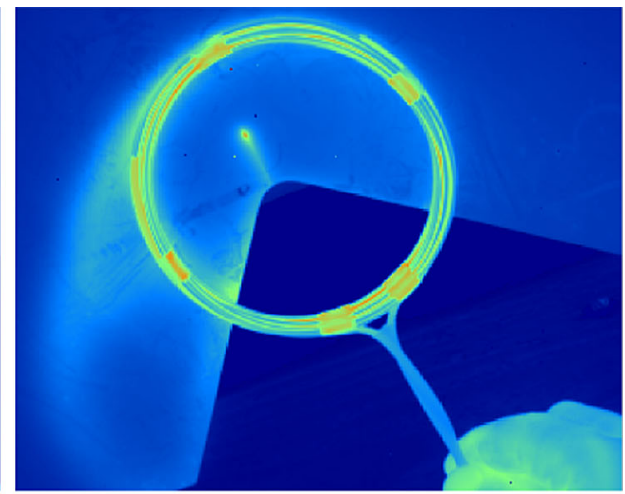

(b) $t=6.55 \mathrm{~s}$

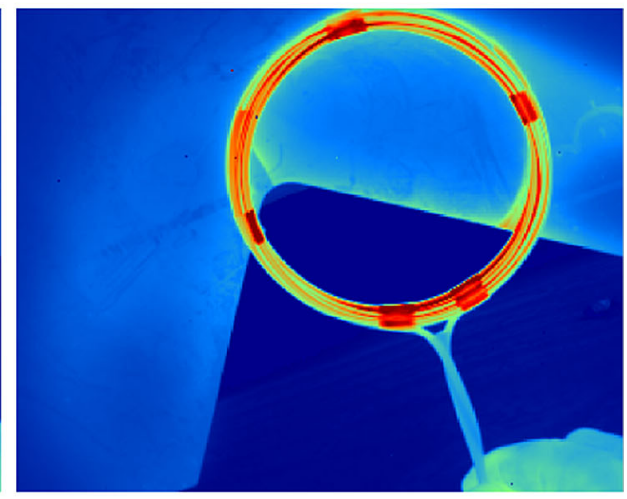

(d) $\mathrm{t}=13.45 \mathrm{~s}$

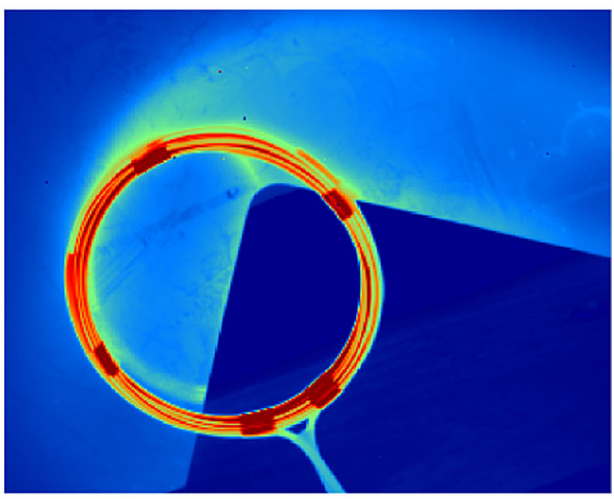

(f) $\mathrm{t}=15.6 \mathrm{~s}$ the switching of the voltage supply and the fast heating and cooling down from the crack tip.

\subsection{Dynamic or Scanning Test}

During the second test, the coil was in motion in order to analyze if an endurance test on larger areas is possible. The average velocity of the coil was $25 \mathrm{~mm} / \mathrm{s}$ and the generation of the current signal was kept switched on for $20 \mathrm{~s}$. As a matter of fact, the permissible time to keep a coil working depends on its technical design.

Figure 12 shows six images of the amplitude video. As can be seen, the visualization of the crack was clear. Thus, the developed system can also be used for testing larger areas in situ.

The variation of the temperature in the pixel corresponding to the crack tip shows that its heating is higher when the coil passes over it, see Fig. 13. 


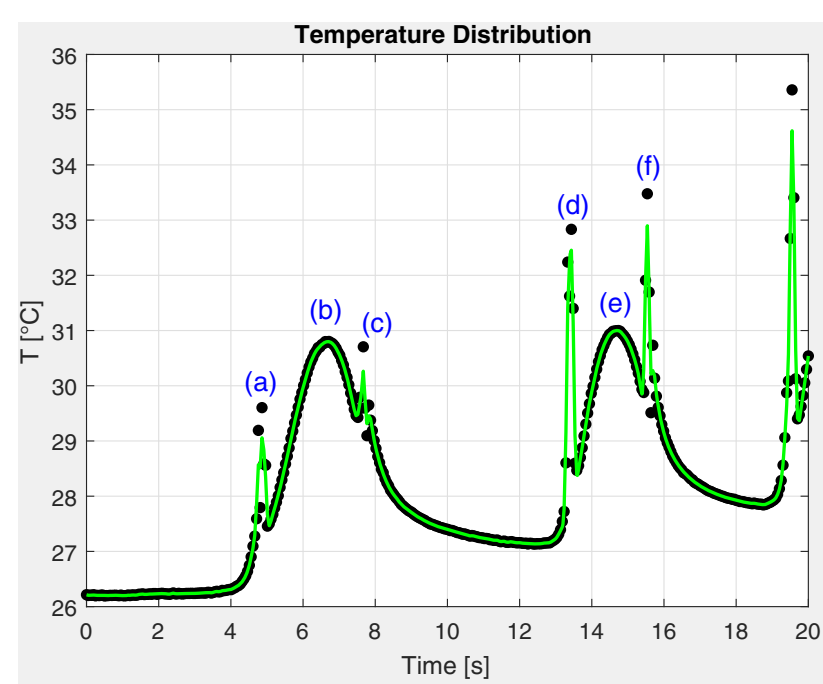

Fig. 13 Variation of the temperature on the pixel corresponding to the crack tip. The points (b) and (e) show the increment of temperature in the crack tip when the coil surrounds it. The points (a), (c), (d), (f) show the pass of the coil over the crack tip. In other words, these points correspond to the temperature of the coil

Since in both applications the crack detection was clear and no subsequent image analysis was required, a trigger to synchronize the signal generation and the IR camera was not necessary.

\section{Conclusions and Subsequent Research}

The experimental method presented in this paper facilitates to test in situ large steel structures on real time under normal environmental conditions. The use of a switched H-Bridge converter allows to optimize and control the signal generation and its related eddy currents. The developed experimental setup has been assembled in a portable prototype which is lighter than $3 \mathrm{~kg}$. Moreover, the subsequent image analysis, the trigger for synchronization and the cooling system are not necessary, and the recording time per area is reduced. Because of these characteristics, the cost and the time of performing this NDT is reduced considerably.

Taken in account that there exist different complex geometries in real steel structures, additional experiments are necessary. These experiments will allow: (a) designing suitable coils to be used within a wide range of geometries and (b) considering the orientation of the cracks in the structure.

Funding Open Access funding enabled and organized by Projekt DEAL.

Open Access This article is licensed under a Creative Commons Attribution 4.0 International License, which permits use, sharing, adaptation, distribution and reproduction in any medium or format, as long as you give appropriate credit to the original author(s) and the source, provide a link to the Creative Commons licence, and indicate if changes were made. The images or other third party material in this article are included in the article's Creative Commons licence, unless indicated otherwise in a credit line to the material. If material is not included in the article's Creative Commons licence and your intended use is not permitted by statutory regulation or exceeds the permitted use, you will need to obtain permission directly from the copyright holder. To view a copy of this licence, visit http://creativecomm ons.org/licenses/by/4.0/.

\section{References}

1. Maldague, X.P.V.: Theory and Practice of Infrared Technology for Nondestructive Testing. Wiley, New York (2001)

2. Meschede, D. (ed.): Gerthsen Physik (Springer-Lehrbuch), 24th edn. Springer, Berlin (2010)

3. Hurley, W.G., Wölfle, W.H.: Transformers and Inductors for Power Electronics. Wiley, New York (2013)

4. Vrana, J., Goldammer, M., Baumann, J., Rothenfusser, M., Arnold, W.: Mechanisms and models for crack detection with induction thermography. AIP Conf. Proc. 975(1), 475-482 (2008)

5. Oswald-Tranta, B., Sorger, M.: Localizing surface cracks with inductive thermographical inspection: from measurement to image processing. QIRT J. 8(2/2011), 149-167 (2004)

6. Zhu, Y.-K., Tian, G.-Y., Lu, R.-S., Zhang, H.: A review of optical NDT technologies. Sensors 11(8), 7773 (2011)

7. Wilson, J., Tian, G., Mukriz, I., Almond, D.: PEC thermography for imaging multiple cracks from rolling contact fatigue. NDT \& E Int. 44(6), 505-512 (2011)

8. Siakavellas, N.J.: The influence of the heating rate and thermal energy on crack detection by eddy current thermography. J. Nondestruct. Eval. 35(2), 29 (2016)

9. Riegert, G., Zweschper, T., Busse, G.: Lockin thermography with eddy current excitation. QIRT J. 1(1/2004), 21-32 (2004)

10. Wullink, J., Darses. Ph.: On-Line Thermography Applied to Crack Detection in Steel Billets. QIRT'2000: Quantitative InfraRed Thermography 5, Number 43 (2000)

11. Goldammer, M., Mooshofer, H., Rothenfusser, M., Bass, J., Vrana, $\mathrm{J}$.: Automated induction thermography of generator components. AIP Conf. Proc. 1211(1), 451-457 (2010)

12. Netzelmann, U., Walle, G.: Induction thermography as a tool for reliable detection of surface defects in forged components. In: 17th World Conference on Nondestructive Testing (2008)

13. Zenzinger, G., Bamberg, J., Dumm, M., Nutz, P.: Crack detection using eddytherm. AIP Conf. Proc. 760(1), 1646-1653 (2005)

14. Zenzinger, G., Bamberg, J., Satzger, W., Carl, V.: Thermographic crack detection by eddy current excitation. Nondestruct. Test. Eval. 22(2-3), 101-111 (2007)

15. Vrana, J.: Grundlagen und Anwendungen der aktiven Thermographie mit elektromagnetischer Anregung. $\mathrm{PhD}$ thesis, Naturwissenschaflich-Technischen Fakultät III, Universität des Saarlandes (2008)

16. Vrana, J., Goldammer, M.: Induction and conduction thermography: from the basics to application. Thermographie-Kolloquium 2017. DGZfP, September (2017)

17. Genest, M., Dudzinski, D.C., Bulmer, S., Kersey, R.K.: Crack detection using induction thermography for thermomechanical fatigue tests. AIP Conf. Proc. 1335, 1727-1734 (2011)

18. Wang, Y., Gao, X., Netzelmann, U.: Detection of surface cracks in metals under coatings by induction thermography. In: 14th Quantitative InfraRed Thermography Conference (2018)

19. Netzelmann, U., Walle, G., Lugin, S., Ehlen, A., Bessert, S., Valeske, B.: Induction thermography: principle, applications and 
first steps towards standardisation. Quant. InfraRed Thermogr. J. 13(2), 170-181 (2016)

20. Tuschl, Ch., Oswald-Tranta, B., Künstner, D.: Schienenprüfung mittels induktiv angeregter thermografie. DACH Jahrestagung (2019)

21. Oswald-Tranta, B.: Induction thermography for surface crack detection and depth determination. Appl. Sci. 8, 257 (2018)

22. An, Q., Hortig, D., Merklein, M.: Infrared thermography as a new method for quality control of sheet metal parts in the press shop. Arch. Civ. Mech. Eng. 12(2), 148-155 (2012)

23. Genest, M., Dudzinski, D.C., Bulmer, S., Kersey, R.K.: Crack detection using induction thermography for thermomechanical fatigue tests. AIP Conf. Proc. 1335(1), 1727-1734 (2011)

24. Trausch, I.: Entwurf und inbetriebnahme einer mosfet hbrückenschaltung für eine zerstörungsfreie werkstoffprüfung. B.Sc. Thesis, Institute of Electrical Engineering (ETI), Karlsruhe Institute of Technology (KIT) (2019)

25. Schwendemann, R.: Inbetriebnahme eines Stromrichters mit SiC-MOSFETS-Sechspulsbrücke und Reglerimplementierung in VHDL. Master's thesis, Intitute of Electrical Engineering (ETI), Karlsruhe Institute of Technology (KIT) (2015)

26. Schwendemann, R., Lorcher, M., Sommer, F., Stefanski, L., Hiller, M.: A new, universal series hybrid cascaded h-bridge converter for power-hardware in the loop emulation. In: 2019 21st European Conference on Power Electronics and Applications (EPE '19 ECCE Europe), pp. P.1-P.10 (2019)

27. Kiep, A., Graovac, D., Pürschel, M.: MOSFET Power Losses Calculation Using the Data-Sheet Parameters. Infineon Application Note (2006)

28. Plum, R., Ummenhofer, T.: Structural-thermal finite element simulation of vibrothermography applied to cracked steel plates. QIRT J. 8(2/2011), 201-220 (2004)
29. Täfler, H.: Numerische Simulation der elektromagnetischen Erwärmung bei Anwendung der Induktionsthermografie. Master's thesis, Versuchsanstalt für Stahl Holz un Steine, Karlsruhe Institute of Technology (KIT) (2014)

30. Toasa Caiza, P.D., Ummenhofer, T.: Lock-in thermography applied to real time crack detection in constructional steelwork. In: Proceedings of 13th International Workshop on Advanced Infrared Technology \& Applications, Area della Ricerca CNR, Pisa, Italy, pp. 270-274 (2015)

Publisher's Note Springer Nature remains neutral with regard to jurisdictional claims in published maps and institutional affiliations. 